\section{REGULAMENTAÇÃO E PSICANÁLISE: DA POLÍTICA À CLÍNICA}

\author{
Regulation and Psychoanalysis: Politics the Clinic
}

Reglamentación y Psicoanálisis: De la Política a la Clínica

Régularisation et Psychanalyse: De la Politique à la Clinique

\section{Resumo}

Este artigo aborda aspectos políticos e clínicos do problema da regulamentação em sua relação com a psicanálise. Na vertente política, destaca-se que as tentativas de regulamentação da psicanálise pelo Estado têm se multiplicado pelo mundo, sendo crucial compreender seu contexto. Na vertente clínica, a regulamentação é vista como um aspecto central das novas configurações culturais, a partir das quais os sintomas se produzem. Busca-se investigar as consequências do privilégio dado ao saber administrativo e burocrático como resposta aos sintomas, bem como propor estratégias clínicas diante desse cenário, especialmente a partir dos conceitos de gozo e objeto $a$.

Palavras-chave: regulamentação; psicanálise; gozo; objeto.

\section{Abstract}

This article discusses political and regulatory aspects of the clinical problem in her relationship with psychoanalysis. On the political aspect, we highlight that the State efforts to regulate psychoanalysis have been increasing around the world, it is crucial to understand its context. In clinical aspect, the regulation is seen as a key aspect of the new cultural configurations, from which the symptoms are produced. The aim is to investigate the consequences of the privilege given to the administrative and bureaucratic knowledge in response to symptoms as well as to propose clinical strategies in this scenario, especially from the enjoyment and object concepts.

Keywords: regulation; psychoanalysis; enjoyment; object.

\section{Resumen}

Este artículo habla acerca de aspectos politicos y clínicos del problema de la reglamentación en su relación con el psicoanálisis. En la vertiente política, se nota que los intentos de reglamentación del psicoanálisis por el Estado se han multiplicado por el mundo, siendo de total importancia la comprensión de su contexto. En la vertiente clínica, la reglamentación es vista como un aspecto central de las nuevas configuraciones culturales, donde los sintomas son producidos. Se busca investigar las consecuencias del privilegio dado al saber administrativo y burocrático como respuesta a los síntomas, así como proponer estrategias clínicas delante de este escenario, especialmente después de los conceptos de gozo y objeto a.

Palabras clave: reglamentación; psicoanálisis; gozo; objeto.

\section{Biopolítica e Subjetividades Contemporâneas}

1) Doutorando do Programa de PósGraduação em Psicanálise da Universidade do Estado do Rio de Janeiro (EURJ). Mestre em Psicologia Clínica pela PUC-Rio.

2) Professora Adjunta do Programa de Pós-Graduação em Psicanálise da Universidade do Estado do Rio de Janeiro. 


\section{Résumé}

Cet article analyse les aspects politiques et cliniques du problème de la régularisation dans sa relation avec la psychanalyse. Du côté de la politique, on détache que les tentatives de régularization de la psychanalyse pour l'État se sont multipliées autour du monde, ce qui montre la grande importance de comprendre son contexte. Du côté de la clinique, la régularisation est vue comme l'aspect central des nouvelles configurations culturelles dont se produisent les symptômes. On recherche analyser les conséquences des privilèges donnés au savoir administratif et bureaucratique comme réponse aux symptômes, et aussi proposer des stratégies cliniques pour cette situation, surtout à partir des concepts de juissance et objet a.

Mots-clés: régularization; psychanalyse; juissance; objet.

Em anos recentes, as tentativas de regulamentação da psicanálise pelo Estado têm se multiplicado pelo mundo. Apesar das particularidades que tal movimento apresenta em cada país, trata-se, inegavelmente, de uma tendência geral. A intervenção direta sobre sua prática não é, contudo, a única razão pela qual o tema da regulamentação interessa ao psicanalista. O movimento regulatório é uma das mais relevantes facetas das novas configurações culturais, nas quais os indivíduos se apoiam e a partir das quais os sintomas se produzem. Por meio de uma contextualização mais ampla do tema da regulamentação, este trabalho pretende correlacionar as duas vertentes citadas, uma política e outra clínica.

Na esfera política, a regulamentação da psicanálise visa à produção de um conjunto de normas burocráticas capazes de responder a questões tão profundas como as seguintes: o que é um psicanalista? Como deve ser sua formação? Que instituições estão aptas a fornecer e a reconhecer essa formação? Em que casos uma análise é indicada? Diante de que sintomas ela comprovou sua eficácia? Quem é responsável por indicar um tratamento psicanalítico?

Esse ímpeto de interferência sobre sua prática, bem como os esforços de responder aos problemas cruciais da psicanálise por intermédio do saber administrativo, tem produzido reações fortes e eficazes da chamada "comunidade analítica", com um grau bastante acentuado de sucesso, até o momento, no rechaço a tais investidas.

Nada indica, contudo, que se trate de um movimento provisório ou declinante.

\section{Panorama da Regulamentação}

Embora a regulamentação seja, de certa forma, inerente a qualquer formação social - vide a anedota segundo a qual Adão e Eva foram suspensos do paraíso em função do consumo não autorizado de um produto regulado -, ela assume características particulares na atualidade, quando desponta como a via privilegiada de exercício dos poderes econômicos, políticos e sociais.

Data de 1962 uma das primeiras publicações a definir o modo de operação do Estado por meio do termo regulamentação. Trata-se do livro The Emergence of the Modern Regulatory State, de James Anderson (1962), que descreve o crescimento da estrutura administrativa do governo dos Estados Unidos (Levi-Faur, 2011).

Em função dessa origem geográfica e do avanço, nas décadas seguintes, das posições econômicas chamadas neoliberais, tendeu-se a correlacionar o exercício regulatório do Estado ao terreno das disputas econômicas.

Sob essa ótica, a ferramenta da regulamentação é compreendida com o modus operandi de um governo mais dedicado à correção das distorções do mercado que ao controle direto das funções econômicas.

Desse modo, quando compreendida no âmbito das reformas neoliberais, a regulamentação tende a ser encarada como a contrapartida da transferência da atuação do Estado para as mãos da iniciativa privada. Em lugar da execução direta de certos serviços, o Estado garantiria apenas que a iniciativa privada se mantivesse dentro de certo conjunto de regras e obrigações de interesse público.

Em resumo, essa tese localiza tanto a origem quanto o contexto privilegiado da regulamentação na passagem do welfare state ao Estado neoliberal.

Embora não seja inteiramente falsa, essa perspectiva comporta o risco de estabelecer uma relação essencial e intrínseca entre regulamentação e neoliberalismo. Trata-se de um fenômeno ideológico, político e economicamente localizado, uma conclusão restritiva, que não permite dar conta do papel exercido pela regulamentação após seu duplo movimento de disseminação: no aspecto político e social, alastrou-se para muitas outras áreas da sociedade; no aspecto geográfico, deixou de ser uma peculiaridade norteamericana e expandiu-se para Europa e América Latina, entre outros locais.

É verdade que seria possível, ainda assim, perseverar na articulação entre regulamentação e neoliberalismo, mediante o argumento de que a lógica neoliberal tampouco se restringiu aos aspectos estritamente econômicos da sociedade, alastrando-se virtualmente para todas as esferas do governo e da sociedade, tais como os cuidados com a saúde, a produção e comercialização de alimentos, as telecomunicações, a aviação civil, os transportes terrestres e aquáticos etc.

Nota-se, contudo, que a ampliação da regulamentação não produziu apenas um enorme alargamento do seu escopo, mas sim uma profunda subversão de sua justificativa conceitual inicial, tornando impossível seguir concebendo-a como o exercício de poderes mínimos necessários ao bom 
funcionamento de certo mercado.

Prefere-se, portanto, encarar a tendência à regulamentação, não tanto com uma opção parcial e particular, mas como uma tendência genérica da cultura, um modo de aplicação do poder em um ambiente marcado pela fragilização dos ideais enquanto referência manifesta para a tomada de decisões.

\section{O Estado Regulador}

Sustenta esse ponto de vista Levi-Faur (2011), um dos maiores estudiosos do mundo sobre o tema da regulamentação, que enxerga "não uma mudança do welfare state para o Estado regulador, mas um resgate regulatório do welfare state" (p. 4). Em sua definição, o Estado regulatório "não é nem neoliberal, nem socialista", ainda que ele reconheça que essa posição contraria a percepção amplamente aceita de que "o Estado regulatório representa a alternativa neoliberal ao Estado positivo" (p. 16). O argumento de base é que a decisão sobre o perfil de certo regime depende de "seus objetivos e dos resultados sociais obtidos, não necessariamente dos instrumentos" (p. 17).

$O$ viés adotado por Levi-Faur é essencial na medida em que concebe a regulamentação como uma ferramenta de poder capaz de ser utilizada por atores de tamanhos, orientações políticas e objetivos muito distintos entre si. Fora dessa abordagem, depara-se rapidamente com uma contradição essencial: se a regulamentação está essencialmente articulada à defesa neoliberal do Estado mínimo, como explicar que ela tem sido a via privilegiada de interferência do Estado nas liberdades individuais? A mesma contradição se manifesta quando se reconhece a profunda antipatia que os liberais nutrem diante dos esforços regulatórios do Estado no seio da vida privada.

Citado por Levi-Faur, Michael Moran oferece um panorama mais amplo do perfil regulatório, não restrito a um viés político específico:

O Estado regulatório é um produto da ascensão da 'escola de governança'- daqueles que enxergam sistemas de governança especiais emergindo para dar conta das condições atuais de alta complexidade. A mudança sutil de "governo" para "governança" busca anunciar o afastamento dos antigos modos de comando da burocracia clássica e hierárquica para um mundo de negociações internas e redes de autocontrole. (Moran, 2000, p. 6)

O "afastamento dos antigos modos de comando" não significa, contudo, que novos modos de comando não passem a operar. Localizá-los por detrás da rede dispersa de regulamentos é uma tarefa essencial, pois evita a ilusão de que o regime da regulamentação abdicaria da imposição de modos de vida. Esse tema será retomado adiante, quando a relação entre a regulamentação e a fragilização dos ideais na cultura for abordada.

\section{Regulamentação: Uma Lógica sem Limites}

Deslanchada, portanto, sob a égide da lógica neoliberal, ocorre uma inversão dramática de seu escopo quando, em lugar de situar-se como contrapartida de uma dispensa de poder direto do Estado, a regulamentação "cria vida própria" e passa a absorver esferas da vida privada que sequer estavam sob o crivo direto do Estado.

A seara econômica oferece um cenário paradigmático dessa inversão, em que a degeneração da função regulatória vem sendo denunciada há muitas décadas, inclusive pelos economistas liberais, que cunharam o termo regulatory capture (captura da regulamentação) para designar a profunda e perniciosa influência que os entes supostamente regulados obtêm sobre os entes supostamente reguladores. Através do poder político e econômico, os entes regulados passam a usar a regulação a seu favor, estimulando a criação de regras que favoreçam seus interesses e alargando as áreas reguladas.

O resultado é a grave fragilização dos dois principais pilares de legitimação da regulamentação: em lugar de uma abdicação de poder por parte do Estado, alarga-se sua capacidade de influência; em lugar da proteção dos interesses públicos, obtém-se o favorecimento dos grupos economicamente mais influentes e organizados.

Em sua análise sobre o tema da avaliação intrinsecamente articulado ao movimento regulatório -, feito na parceria do psicanalista Jacques-Alain Miller, Jean-Claude Milner insiste no seguinte alerta: "Conservase, vinda do passado, uma função régia do Estado, mas ela vai se ocupar de todos os elementos que compõem a vida pública moderna. Entre esses elementos, a saúde pública, e entre os elementos da saúde pública, a saúde mental, entre os elementos da saúde mental, o mal viver" (Miller \& Milner, 2004, p. 28).

Ao analisar esse mesmo cenário, Levi-Faur (2011) detecta uma profunda transmutação dos poderes do Estado, que passa a reivindicar o "legítimo monopólio sobre o desenvolvimento e a distribuição do poder através da produção, do monitoramento e da execução de regras" (p. 14). O contraste se estabelece aqui entre essa reivindicação, a qual o Estado pode delegar ou dividir, e a definição clássica do Estado proposta por Max Weber, que o descreve como "uma comunidade humana que pretende o monopólio do uso legítimo da força física dentro de um determinado território" (Weber, 1982, p. 97).

No que concerne ao campo em que se insere a psicanálise, o paradigma regulatório, mais que estabelecer fronteiras comportamentais aceitáveis no seio de certa sociedade - criminalizando, por exemplo, uma série de 
condutas -, atrai para o crivo da regulamentação a inteireza da experiência humana, mesmo aquela que não recorre ou atenta contra o uso da força. Nesse contexto, adverte Miller e Milner (2004, p. 71): "falar da saúde mental como uma extensão da saúde pública é, na verdade, estender a esfera do público de tal forma que a esfera do privado seja inteiramente absorvida nela".

O cenário político que se instala sob a égide do binômio regulação/avaliação é descrito por Milner através do paradigma problema/solução. A partir do momento em que uma queixa se manifesta na sociedade, demanda-se aos políticos que encontrem uma solução. $\mathrm{Na}$ direção de sua ponderação de que "é inútil procurar saber se essa queixa é bem fundada ou se é massiva" (Miller \& Milner, 2004, p. 72), poder-se-ia acrescentar a possibilidade de que a oferta de uma solução crie retroativamente a crença de que existia um problema.

A amplitude dessa transformação e a profundidade das raízes históricas em jogo são descritas por Agamben na seguinte passagem, que merece ser reproduzida:

Enquanto a cidadania grega se definia pela oposição entre o privado e o público, a casa (sede da vida reprodutiva) e a cidade (lugar do político), a cidadania moderna parece evoluir numa zona de indiferenciação entre o público e o privado, ou, para tomar emprestadas as palavras de Thomas Hobbes, entre o corpo físico e o corpo político. [...] Tal transformação tem uma multiplicidade de causas, entre as quais o desvio do poder moderno em relação à biopolítica ocupa lugar especial: trata-se de governar a vida biológica dos indivíduos (saúde, fecundidade, sexualidade etc.), e não mais apenas exercer uma soberania sobre o território. (Agamben, 2014, p.3)

\section{Autonomia da Regulamentação}

Depois de abordada a passagem para o Estado regulatório, é preciso perceber um segundo movimento: a crescente autonomia das agências e demais atores reguladores e o consequente distanciamento entre esses e os organismos clássicos de representação política.

Diante dessa mudança, Levi-Faur chega a propor a expressão "novo Estado regulatório" e descreve o seguinte cenário:

As funções reguladoras do governo estão sendo separadas das funções de formulação de políticas; a autonomia dos reguladores é institucionalizada e, assim, amplia ainda mais a esfera de formulação de diretrizes "apolíticas". As agências reguladoras se tornaram as cidadelas que fortaleceram o papel autônomo e influente dos regulocratas no processo decisório. Estamos testemunhando o fortalecimento dos órgãos reguladores, em detrimento dos políticos. (Levi-Faur, 2011, p. 12)

Jacques-Alain Miller enxerga a mesma fragilização da política e frisa o papel da avaliação nesse processo: "A avaliação é o poder administrativo se impondo aos agentes políticos, atravessando governos que são apenas epifenômenos. $\mathrm{O}$ poder administrativo se impôs aos políticos, eles abaixam a cabeça. É preciso ajudá-los a levantar" (Miller, 2014, p. 40).

Vê-se que é inerente a esse processo uma crescente especialização das normas e das próprias agências reguladoras, que lidam com temas cada vez mais complexos e demandam, portanto, um exército cada vez maior de experts.

Paralelamente, observa-se não apenas a multiplicação dos organismos reguladores como sua descentralização e até mesmo o rompimento das fronteiras nacionais, por meio da criação de organismos reguladores cujo poder de ação se estende a blocos continentais ou simplesmente não guarda relações com regiões geográficas.

Levi-Faur (2009) oferece um alerta contundente sobre processo:

A produção e a distribuição dos produtos que consumimos, dos serviços que contratamos e nosso meio ambiente são todos moldados por milhares de regulamentos que foram decididos fora dos nossos parlamentos e poderes executivos e para além da jurisdição de nossos tribunais nacionais (Braithwaite \& Drahos, 2000). Estes regulamentos moldam os medicamentos e alimentos que consumimos, a qualidade do ar que respiramos e da água que bebemos, e a segurança dos brinquedos dos nossos filhos. (Levi-Faur, 2009, p. 1)

Assim, é preciso fazer um rápido parêntese e reconhecer que, até o momento, as tentativas de regulamentação da psicanálise ainda se dão no nível dos órgãos clássicos de representação política - mais especificamente no Poder Legislativo, através de projetos de lei. Isso se deve ao fato de que, em alguns casos, ainda é necessária uma chancela legal inicial, para que as agências reguladoras assumam em seguida o aprofundamento da tarefa.

Por outro lado, é inegável que o paradigma de gestão pública que inspira tais esforços não é propriamente o do regime jurídico clássico, mas sim a afirmação subjacente de que os cidadãos estão diante de inumeráveis perigos que não podem ser superados por seu poder individual de escolha, senão por uma constante e exaustiva intervenção do Estado, que criaria um conjunto infinito de regras, capazes de avaliar e evitar cada um desses riscos.

Diante desse cenário, contudo, é razoável esperar que a arena na qual há a batalha pela regulamentação da psicanálise, atualmente, ainda sofra importantes modificações. Os 
órgãos de representação política, tal como o Poder Legislativo, têm acolhido demandas de regulamentação nas quais os argumentos de base ainda são os da distribuição de poder entre profissões, do reconhecimento de categorias profissionais etc. A partir do momento em que esse passo for dado, a "profissão psicanalista" está radicalmente sujeita a prestar conta de sua relação custo/benefício e de sua eficácia a agentes ou agências reguladoras não sediadas nos órgãos de representação política, cuja linguagem oficial é a das cifras e da burocracia.

Sob o argumento quase irrefutável do bem comum e da proteção do bem-estar dos indivíduos, a psicanálise tende a ser gravemente ameaçada pela única referência universalmente aceita como régua de medida: o discurso da ciência, ou sua degeneração, que consiste em um uso deturpado e indecente da cifra como chancela científica.

\section{O Declínio dos Ideais}

O ambiente cultural no qual a ascensão da regulamentação ocorre vem sendo profundamente estudado pela psicanálise, especialmente a partir do ensino de Jacques Lacan.

Nesse contexto, um importante marco teórico foi o seminário proferido em 1996 por Jacques-Alain Miller, em parceria com Eric Laurent, cujo título é por si só a nomeação de sua hipótese de leitura: "O Outro que não existe e seus comitês de ética" (2005).

Nele, analisam os efeitos do avanço dos discursos capitalista e científico, cuja "dominação combinada, cada um se apoiando no outro, tem crescido a tal ponto que tem conseguido destruir até os fundamentos mais profundos da tradição" (Miller, 2012, p. 1).

$\mathrm{Na}$ tradição, o acesso ao Outro era mediado pela identificação com uma particularidade, que invariavelmente tomava a forma de uma comunidade, cuja consistência dependia dos ideais. As identidades tendiam, assim, a recorrer ao material simbólico tradicional de certa comunidade, em torno do qual o pertencimento era obtido. Nesse ambiente clássico, o problema da satisfação pulsional tomava fundamentalmente a forma da castração.

A profunda correlação entre esse momento da civilização e a teoria da psicanálise é apontado por Miller (2002), quando afirma que "todo o aparelho conceitual freudiano continua marcado pela época disciplinar: interdito, recalcamento, repressão, censura...” (p. 26).

$\mathrm{Na}$ contemporaneidade, pelo contrário, é possível reconhecer que a busca de satisfação é não apenas autorizada como incessantemente exigida. A satisfação não é orientada pelos ideais e sua exigência de castração, mas sim pelo seu suposto preenchimento, o que Lacan (2008) chamou de mais de gozar ou, simplesmente, objeto $a$.

Trata-se de um profundo corte na civilização, que, segundo Miller, corresponde à saída da época disciplinar: "Tudo é agora uma questão de arranjo. Não se sonha mais com o fora. Há apenas percursos, arranjos e regimes de gozo" (2002, p. 28).

A horizontalidade dessa lógica permite sonhar com um reino inclusivo, em que todos os modos de gozo podem conviver em harmonia e a civilização deixaria de exercer o papel repressor que estaria na base da neurose. Esse seria provavelmente o ideal liberal por trás das melhores concepções da globalização.

É um sonho que Lacan não se permitiu sonhar.

\section{Universalismo e Segregação: O Alerta de Lacan}

Lacan soou o alarme antes que fosse possível realmente compreendê-lo. Quando as fantasias globalizantes de um mundo sem fronteiras não haviam ainda desembocado em formações geopolíticas concretas, ele alertou:

Creio que, em nossa época, a marca, a cicatriz da evaporação do pai é aquela que nós podemos colocar sob a rubrica e o título geral de segregação. Pensa-se que o universalismo, a comunicação de nossa civilização homogeneíza as relações entre os homens. Eu penso, ao contrário, que o que caracteriza nossa época - e nós não podemos nos dar conta disso - é uma segregação ramificada, reforçada, que produz pontos de cruzamento em todos os níveis e que não faz senão multiplicar as barreiras. (Lacan, 2003, p. 9)

Eric Laurent extrai a lógica subjacente à posição de Lacan:

Não sabemos o que é o gozo segundo qual poderíamos nos orientar. Sabemos apenas rejeitar o gozo do outro [...]. Essa lógica coletiva está fundada na ameaça de uma rejeição primordial, de uma forma de racismo: o homem sabe o que não é um homem. (2013, p.31)

A leitura de Laurent extrai duas consequências, interligadas, da formulação de Lacan. A primeira atribui ao gozo o caráter problemático das formações sociais, uma ideia que certamente remonta e se alinha aos textos freudianos sobre o mal-estar na cultura. A segunda, no entanto, comporta um deslocamento em relação às contribuições de Freud, notadamente aquelas incluídas em Psicologia das Massas.

Trata-se do novo caminho descrito por Lacan para a construção do laço social: em vez da identificação ao pai, ao líder ou a um ideal oferecido pela cultura, sobrevém a função fundadora da segregação. A exclusão do gozo do outro se torna essencial para a constituição das comunidades, que 
merecem agora ser chamadas "comunidades de gozo", pois aquilo que as reúne é justamente um modo de obter satisfação.

Vê-se que, às constatações sobre o papel contemporâneo da regulamentação, a psicanálise permite acrescentar a dimensão libidinal nele implicada. Para retomar a questão do panorama da regulamentação trabalhado no início do artigo, pode-se sugerir agora que não se trata apenas de notar seu alastramento, mas de constatar que ela é hoje o principal instrumento político de mediação dos embates segregativos. Nesse contexto, segundo Laurent, "o Estado ou a instância regulatória devem simplesmente arbitrar as exigências rivais dos indivíduos" (2005, citado por Miller, 2005, p. 145).

Em torno do discurso cientificista, em torno das cifras, em torno da infinidade das normas, exclui-se o gozo do outro, reinventa-se constantemente o tecido social e produzse, por exclusão, uma particularidade universalmente representável, num movimento horizontal, perpétuo e dependente do lobby.

O sonho de uma universalidade sem fronteiras transforma-se no retorno, ainda que bastante modificado, da criação de comunidades. Segundo Miller, "Lacan anunciava que, dissolvida a particularidade, esta tenderia inevitavelmente a se reconstituir no seio do universal, ainda que sob a forma de segregações múltiplas" (2005, p. 72).

Nessa arena, cada particularidade busca efetivar a universalidade por ela vislumbrada, ainda que através da produção de normas, e não do fortalecimento das grandes narrativas universais.

\section{O Litígio como Laço Social?}

Em uma de suas muitas análises sobre as consequências políticas desse cenário, Miller recorre a uma citação do filósofo e historiador Marcel Gauchet: "É nisto que consiste especificamente a política: ela é o lugar de uma fratura da verdade" (2002, p. 21).

A fratura, segundo Miller, se dá em relação aos totalitarismos, que permitiam a esperança de superar a divisão da verdade, de instaurar o reino do Um no exercício da política (2002, p. 22). Apesar de sua evidente face violenta, mantinha-se nesses regimes a ilusão de uma sociedade una, em absoluta harmonia consigo mesma.

Já no contexto democrático, pondera Gauchet, citado por Miller,

Estamos destinados a encontrar o outro sob o signo de uma oposição sem violência, mas também sem retorno, nem remédio. Encontrarei sempre diante de mim não um inimigo que deseja minha morte, mas um contraditor. Há qualquer coisa de metafisicamente aterrorizante nesse encontro pacificado. (Gauchet, 2002, p. 21)
É preciso ponderar, no entanto, que não existe uma coincidência temporal estrita entre a democracia como regime político e a generalização dessa "fratura da verdade". Embora a democracia seja certamente um regime mais favorável à fragilização dos ideais, nem por isso é impossível concebê-la como uma mediação da luta entre grandes narrativas.

O cenário que se descreve, portanto, não é simplesmente o da operação da democracia enquanto regime de governo, mas o da democracia em sua face mais vazia e horizontal, aquela que coincide com a derrocada dos ideais enquanto pilares do debate político.

Dispersos os ideais, o regime democrático caminha para uma pulverização estonteante dos atores políticos. Nesse contexto, praticamente qualquer comunidade de gozo pode ser reconhecida e ter seus direitos ampliados, desde que constituído em um agrupamento politicamente atuante.

À vertente libertária dessa proposta se contrapõe a inescapável instrumentalização do conflito pela burocracia, pelo inferno dos lobbies e pela judicialização da diferença.

Se, por um lado, é possível celebrar o alargamento das possibilidades individuais permitido pela fragilização dos ideais, por outro, a civilização se vê condenada ao litígio ininterrupto, cujo poder de aplicabilidade depende cada vez mais da regulamentação.

\section{Ausência de Ideal?}

É possível retomar agora a questão brevemente mencionada sobre o caráter supostamente antagônico entre a regulamentação e os ideais.

Embora seja indiscutível que a regulamentação como forma de exercício de poder é uma decorrência do declínio dos ideais na cultura, cabe interrogar se se está diante de uma mera balança, em que um lado ascende quando o outro descende, ou diante de uma relação mais complexa.

A possibilidade de conceber essa articulação de forma menos horizontal pode ser sustentada pelas elaborações lacanianas sobre os modos de estabilização dos laços sociais, através dos discursos. Embora não se possa neste artigo apresentá-los de forma detida, deles extraímos uma orientação: há o lugar do agente e o lugar da verdade, e eles não coincidem. O modo como cada um desses espaços é ocupado é determinante para o laço social, mas o agente tende a ser mais manifesto e evidente que a verdade.

O cenário descrito pode ser entendido como a operação da regulamentação/avaliação no lugar do agente enquanto os ideais e as aspirações totalitárias se revelam como sua verdade. Trata-se do que Lacan chamou "discurso universitário".

Ainda que seja inerente ao funcionamento de agências reguladoras lançarem mão de uma lógica avaliável, 
quantificável e pragmática como meio de aplicação e produção de regulação, é impossível ignorar que seus efeitos não são menos severos por não ostentarem uma narrativa calcada num material simbólico tradicional.

A diferença em relação ao regime tradicional é que o sentido do campo político passa a depender, para cada um, da inscrição e do reconhecimento de seu modo de gozo.

O desvelamento desse processo, realizado por Agamben, é contundente:

Creio que poderíamos fornecer uma boa descrição das sociedades pretensamente democráticas nas quais vivemos através da simples constatação que a ontologia do comando tomou o lugar da ontologia da afirmação, mas não sob a forma clara de um imperativo, mas sob aquela, mais insidiosa, do conselho, do convite, do alerta, dados em nome da segurança, de modo que a obediência a uma ordem toma a forma de uma cooperação e, frequentemente, a de um comando dado a si mesmo. (Agamben, 2013, p. 48)

Assim, embora a produção e a execução de regras não se deem sob a égide das grandes narrativas ou de ideais manifestos, nada indica que os múltiplos valores que informam e orientam a tomada de decisões reguladoras não estejam ligados ao escopo daquilo que pode ser perfeitamente transformado em ideal. A diferença crucial é que, no lugar do agente dessa intervenção, encontra-se um arcabouço administrativo, anônimo e numérico.

Nesse processo, pode estar incluída uma gama de posturas distintas, desde a manipulação canalha do saber pseudocientífico até a ilusão ingênua de que a dimensão decisória inerente às construções sociais poderia ser dispensada em favor de escolhas meramente técnicas.

No que tange às grandes questões, contudo, a lógica avaliacionista não permite a produção de grandes decisões, e não se crê ser verdade que se está no império das pequenas decisões. O modelo matemático não fornece respostas definitivas para as escolhas políticas, sociais, econômicas e biológicas a serem tomadas. Do ponto onde se situa, o da psicanálise, é crucial não levar longe demais a perspectiva de que a burocracia assumiu o comando da tomada de decisões. É preciso reconhecer, estudar e interpretar o que há de verdade nessa afirmação. Mas é igualmente necessário indicar o ponto em que a burocracia se torna antes um veículo que uma razão.

Sustentamos, portanto, que o uso do binômio regulação/ avaliação apoia-se na lógica científica da especialidade, não como forma de dispensar ideais, mas como forma de legitimação das decisões políticas. Seria ingênuo, em suma, crer que a lógica da cifra pode de fato operar de forma autônoma e automática, sem estar informada por uma pluralidade de fragmentos ideológicos e até mesmo sistemas de pensamento.
Recorre-se novamente a Levi-Faur, quando adverte que "questões de licença maternidade e paternidade, abuso sexual e outros tipos de abuso no local de trabalho, ética em pesquisa, horas de trabalho, indenização, igualdade de oportunidades são todas questões que são promovidas e executadas através de regulamentação" (2011, p. 25).

Quando se combinam os dois cenários anteriormente descritos e defendidos - a independência dos agentes reguladores e a impossibilidade de que não se carreiem ideais nesse processo -, o resultado é a constatação de que se caminha não para uma civilização sem ideais, mas para uma cujos ideais que definem seus rumos não mais são apresentados e defendidos enquanto tais, e sim postos em operação através de um aparato burocrático que não está obrigado a responder aos poderes políticos.

O grande perigo da operação combinada do binômio regulação/avaliação não é, portanto, o aniquilamento da necessidade da decisão, mas sim a colocação de um anteparo quase intransponível entre a decisão e sua causa real.

Essa perspectiva evita que a posição do psicanalista no debate cultural e político consista apenas na denúncia do vazio, da perdição, da frivolidade. Duas vias se abrem: localizar os arroubos totalitários imiscuídos nas cifras da regulação e esclarecer os modos de segregação que delas derivam.

No que diz respeito à clínica, encontra-se em Laurent uma pista para fazer essa passagem: "Existe uma dimensão que se deve ter conta: a dimensão da consistência de gozo dessas diferentes comunidades, nas quais se trata de fazer 'desconsistir', tornar inconsistente justamente aquilo que pode sempre cristalizar-se no combate de uma particularidade contra outra" (2010, p. 44).

\section{Desconsistir o Gozo?}

A hipótese é que a ideia de "fazer desconsistir" os gozos que se apresentam como traço de identidade abre a via para pensar uma direção clínica dos tratamentos.

$\mathrm{Na}$ conferência "Uma fantasia", Jacques-Alain Miller (2006) apontou a dificuldade que se coloca para a clínica psicanalítica diante de sintomas marcados pela presença evidente da satisfação pulsional. De um modo paradoxal, essa "ascensão ao zenith" do objeto $a(2006$, p. 7) produz uma estranha equivalência com o discurso da psicanálise, no qual o objeto $a$ está igualmente na posição de agente.

A dificuldade clínica que se observa com frequência é a impossibilidade de "fazer os sintomas falarem", de articulálos à cadeia de sentidos que levariam à operação da função do sujeito suposto saber e à paulatina construção da fantasia.

Rompe-se, dessa forma, um canal tradicional de entrada em análise, que Lacan descreve da seguinte forma: "Digam vocês o que disserem, existe o Outro, o Outro que sabe o que isso quer dizer" (2008, p. 333). Um Lacan otimista 
chega a afirmar, quanto ao neurótico, que "no início da experiência analítica, não temos nenhuma dificuldade para incitá-lo a confiar nesse Outro como o lugar em que o saber se institui" (p. 333).

Quando não mais se pode afirmar que "não temos nenhuma dificuldade", de que outra forma é possível formalizar a entrada em análise? Para além da faceta de exigência superegoica de satisfação que dá o tom da civilização, como fazer, na clínica, o bom uso do objeto $a$ ?

Entende-se que Laurent chama de "consistência dos modos de gozo" a sua fixação em uma identidade e em uma coletividade, sem que as marcas singulares do desejo do Outro se articulem ao objeto $a$.

Fazê-lo "desconsistir", nesse sentido, não seria propriamente combatê-lo ou esvaziá-lo, mas sim separálo do invólucro emudecido que a identificação a uma comunidade engendra. $\mathrm{O}$ uso do modo de gozo para forjar identidades tende a camuflar os detalhes singulares que se ligam sempre à obtenção da satisfação, em favor dos traços partilháveis, nomeados por significantes comuns ao grupo.

Enquanto traço identitário, portanto, o objeto $a$ liga o sujeito a um Outro regulatório, composto pelos conjuntos dos lobbies dos modos de gozo. É o Outro anônimo cuja resposta é a regulamentação, a cifra.

A produção de nomeações artesanais para um modo de gozo, tecidas no início da experiência analítica, pode permitir a entrada em cena de um outro regime de saber.

Não se trata tanto de apostar na decifração do sintoma, mas sim na presença do analista como encarnação de um desejo que não seja anônimo, atento à produção de nomeações que descolem o sujeito tradução habitual e coletiva de seu modo de gozo.

Apesar da estranha coincidência que se poderia forjar entre o discurso da psicanálise, em cujo lugar de agente encontra-se no objeto $a$, e o regime de gozo da contemporaneidade, a clínica psicanalítica extrai do objeto $a$ é uma consequência muito distinta.

Em vez de conduzir o objeto a "consistir" em uma identidade, a margem fina em que a psicanálise opera faz do objeto a a matéria do desejo do Outro. A psicanálise distingue-se, assim, da ciência e da regulamentação: o saber que ela encontra no real não tem a duração científica de uma eternidade, nem a autoria de um agente despido de desejo.

Diante do gozo opaco do sintoma, mais do que se propor como a ponte de certeza de que ligaria o gozo ao sentido, a análise reconhece nos objetos de gozo a dimensão paradoxal do sujeito: sempre marcado pelos significantes do Outro e, ao mesmo tempo, por um ponto cego.

Se a resposta contemporânea ao ponto cego do gozo é o esforço contínuo de ciframento e identificação, a psicanálise convida a encontrar nesse ponto cego os pontos cegos dos Outros que tomaram um sujeito como objeto causa de desejo.

O Outro que a experiência da análise permite

materializar através dos objetos de gozo é um Outro desejante e, portanto, inconsistente. Essa aproximação entre o objeto $a$ e o Outro foi tema de um fantástico seminário de Lacan, o Seminário 16: De um Outro ao outro (19681969/2008), em que ideia de que o Outro pode vir a sustentar-se justamente a partir dos objetos ganha inclusive um nome: Outro em-fôrma de a.

Propõe-se, assim, a seguinte tradução para a ideia de Laurent, de "fazer desconsistir" os modos de gozo: trata-se de ligar o singular ao universal, sem passar pelo particular da identificação.

\section{Referências}

Agamben, G. (2013). Que'est-ce que le commandement?. Paris: Éditions Payot et Rivages.

Agamben, G. (2014, 06 de janeiro). Como a obsessão por segurança muda a democracia. Le Monde Diplomatique. Recuperado da base de dados de Le Monde Diplomatique: http://www.diplomatique.org. br/artigo.php?id=1568

Anderson, J. E. (1962). The Emergence of the Regulatory State. Washington: Public Affairs Press.

Klein, J. (2003). For All These Rights: Business, Labor and the Shaping of America's. Public-Private Welfare State. Princeton: Princeton University Press.

Lacan, J. (2003). Nota sul padre e l'universalismo. La Psicoanalisi. 33, Studiinternazionali del campo freudiano. Roma: Astrolábio.

Lacan, J. (2008). O Seminário: Livro 16. De um Outro ao outro. Seminário de 1968-69. Rio de Janeiro: JZE.

Laurent, E. (2010). Psicoanálisis y política. In El goce sin rostro. Buenos Aires: Tres Haches.

Laurent, E. (2013). O racismo 2.0. In Opção Lacaniana n.67. São Paulo: Edições Eólia.

Levi-Faur, D. (2009). Regulatory Architectures for a Global Democracy. In P. Tony, \& K. Ronit, The Challenges of Global Business Authority. New York: Suny University Press.

Levi-Faur, D. (2011). The odyssey of the regulatory state. Jerusalem Papers in Regulation \& Governance, 39.

Miller, J.-A., \& Milner, J.-C. (2004). Voulez-vous être évalué? Entretiens avec une machine d'imposture. 
Paris: Grasset.

Miller, J-A. (2002). Intuitions milanaises 1. Mental-Revue Internationale de Santé Mantale et Psychanalyse Appliquée, 11, 17.

Miller, J-A (2005) El Outro que no existe y sus comités de ética/ con colaboración de Eric Laurent. Buenos Aires: Paidos.

Miller, J.-A. (2006). Uma fantasia. Opção Lacaniana, 42. São Paulo: Edições Eólia.

Miller, J.-A. (2012). Apresentação do tema do IX Congresso da AMP. Recuperado da base de dados da Associação Mundial de Psicanálise: http://congresamp2014.com/ pt/Print.php?file $=$ Textos/Presentation-du-theme Jacques-Alain-Miller.html

Moran, M. (2000). From Command State to Regulatory State? Glasgow: Public Policy and Administration.

Weber, M. (1982). Política como Vocação. In Ensaios de Sociologia (pp. 97-153). Rio de Janeiro: Livros Técnicos e Científicos Editora.

\section{Endereço para correspondência:}

Rodrigo Lyra

Endereço: Rua Jardim Botânico, no 635/204, Jardim

Botânico, Rio de Janeiro/RJ. CEP: 22470-050.

E-mail: rodlc@globo.com

\section{Endereço para correspondência:}

Heloisa Caldas

Endereço: Rua Joaquim Campos Porto, $n^{\circ}$ 267. Jardim Botânico, Rio de Janeiro/RJ. Cep: 22460-190.

E-mail: helocaldas@terra.com.br 